\title{
THE EFFECT OF BREASTFEEDING AND ITS DURATION ON ACUTE OTITIS MEDIA IN CHILDREN IN BRNO, CZECH REPUBLIC
}

\author{
Ermis Vogazianos ${ }^{1,2}$, Paris Vogazianos ${ }^{2}$, Jindřich Fiala ${ }^{2}$, Dalibor Janeček ${ }^{1}$, Ivo Šlapák ${ }^{1}$ \\ ${ }^{1}$ Department of Paediatric Otorhinolaryngology, University Hospital, Brno, Czech Republic \\ ${ }^{2}$ Department of Preventive Medicine, Faculty of Medicine, Masaryk University, Brno, Czech Republic
}

\section{SUMMARY}

Aim: We designed this study to assess the effect of breastfeeding and its duration on acute otitis media (AOM) in children of our geographical region. Our main aim was to determine the period of breastfeeding, necessary to achieve optimal preventive results against AOM.

Methods: The children that, according to the questionnaire, had suffered AOM infections in the past were used as the study group with the rest of the children used as control. The duration of breastfeeding was divided into months and the odds ratios for the occurrence of AOM were calculated for the children breastfed for more than or equal to a certain period, compared to the children breastfed for less than that period. This was repeated for each month separately and the results plotted on a graph of the confidence interval $(\mathrm{Cl})$ for the odds ratio values, against months of breastfeeding.

Results: The results of our study show that breastfeeding for a period of up to 11 months can play a significant preventive role against AOM (odds ratio and lower $90 \% \mathrm{Cl}>1$ ). Breastfeeding for longer periods of time is also beneficial, with breastfeeding up to 18 months being associated with some preventive effect against the disease (odds ratio $>1$ ), but the reduction in the incidence of AOM is not statistically significant after the 11th month. Furthermore, there are marked differences in the importance of breastfeeding during the first 11 months, with a vital protective effect during the first 4 months of life which, however, drops by the 5th month and then rises again from the beginning of the 6th to the end of the 8th month. The protective effect then drops once more, although it remains positive and statistically significant until the 11th month of life and positive, but not statistically significant, until the 18th.

Conclusion: Our study has revealed that for an optimal preventive effect to be achieved, the child should be breastfed for at least the first 11 months of its life. Continuing after this for up to the 18th month shows some preventive effect, which however is not statistically significant. Our results support the hypothesis that the importance of breastfeeding varies with the development of the child, its changing environment and to the new immunological challenges this brings.

Key words: breastfeeding, acute otitis media, prevention, duration, paediatrics, otorhinolaryngology

Address for correspondence: J. Fiala, Dept. of Preventive Medicine, Tomešova 12, 60100 Brno, Czech Republic. E-mail: jfiala@med.muni.cz

\section{INTRODUCTION}

Research has shown a significant protective role of breastfeeding against Otitis Media (OM) $(1,2)$ and has indicated the importance of a minimal duration of it, in order to achieve the expected benefit against Acute Otitis Media (AOM) (2-9).

The recommended period of breastfeeding for the optimal results against AOM varies from study to study. Some studies have suggested that exclusive breastfeeding for at least 4 months is enough to protect infants from single and recurrent episodes of $\mathrm{OM}$ (6). Other studies have shown that the peak incidence of AOM episodes was inversely related to rates of breastfeeding beyond 3 months of age (7). Daly et al. also showed that children who were exclusively breastfed for 6 months had significantly fewer episodes of early AOM than children not exclusively breastfed this long (8). The same was true for children who were exclusively breastfed for 3 months but to a lesser extent (8). Aniansson et al. have shown that the first AOM episode occurred significantly earlier in children who were weaned before 6 months of age. The AOM frequency was also significantly lower in children breastfed for up to 10 months, compared to non-breastfed children (9). Dewey et al. have shown that during the first year of life, the incidence of AOM was significantly higher among formula-fed infants than among breastfed infants (10). The number of episodes per year was also higher among formula-fed infants compared to breastfed infants (10). Finally, Chantry et al reported increased risk of recurrent $\mathrm{OM}$ in children who were fully breastfed for 4 vs 6 months (2). Other studies have shown that long periods of breastfeeding have no side effects on the babies' health $(11,12)$ but after a certain point prolonged breastfeeding does not offer 
any extra protection against AOM (13). These studies, however, were not specifically focused on AOM.

The World Health Organisation (WHO) recommends exclusive breastfeeding for the first 6 months of life and continuation of breastfeeding for up to 2 years (14).

Our study was designed in order to investigate the effect of breastfeeding and its duration, on the incidence of AOM, in a cohort of children residents of the city of Brno in the Czech Republic. Our aim was to determine the minimum period for which a child must be breastfed, in order to achieve the optimal preventive effect against AOM.

\section{MATERIAL AND METHODS}

The history of breastfeeding, for 281 children that came to our clinic to be operated for adenoid hypertrophy, was taken, with the help of a questionnaire handed out to the parents, before the operation. The children that, according to the questionnaire, had suffered AOM infections in the past, were used as the study group, whereas the rest of the children were used as the control.

The duration of breastfeeding was divided into months and the odds ratios for the occurrence of AOM were calculated for the children breastfed for more than or equal to a certain period, compared to the children breastfed for less than that period. This was repeated for each month up to, and including, one year and 18 months of breastfeeding, separately. The results were plotted on a graph of the confidence interval for the odds ratio values against months of breastfeeding.

\section{RESULTS}

The results (Fig. 1 and Table 1) show that exclusive breastfeeding for a period of up to 11 months can play a significant protective role against AOM (odds ratio and lower 90\% CI >1). Breastfeeding past the 11th month does not show a statistically

Table 1. The occurrence of AOM. according to the duration of breastfeeding in months

\begin{tabular}{|c|c|c|c|c|c|c|}
\hline Months & Otitis & No otitis & $\begin{array}{l}\text { Odds } \\
\text { ratio }\end{array}$ & $\begin{array}{c}\text { Standard } \\
\text { error }\end{array}$ & $\begin{array}{l}\text { Upper } \\
90 \% \mathrm{Cl}\end{array}$ & $\begin{array}{l}\text { Lower } \\
90 \% \mathrm{Cl}\end{array}$ \\
\hline$\leq 1$ & 21 & 26 & \multirow{2}{*}{1.93} & \multirow{2}{*}{0.33} & \multirow{2}{*}{3.32} & \multirow{2}{*}{1.13} \\
\hline$>1$ & 66 & 158 & & & & \\
\hline$\leq 2$ & 34 & 47 & \multirow{2}{*}{1.87} & \multirow{2}{*}{0.28} & \multirow{2}{*}{2.95} & \multirow{2}{*}{1.19} \\
\hline$>2$ & 53 & 137 & & & & \\
\hline$\leq 3$ & 45 & 71 & \multirow{2}{*}{1.71} & \multirow{2}{*}{0.26} & \multirow{2}{*}{2.63} & \multirow{2}{*}{1.11} \\
\hline$>3$ & 42 & 113 & & & & \\
\hline$\leq 4$ & 51 & 87 & \multirow{2}{*}{1.58} & \multirow{2}{*}{0.26} & \multirow{2}{*}{2.43} & \multirow{2}{*}{1.02} \\
\hline$>4$ & 36 & 97 & & & & \\
\hline$\leq 5$ & 54 & 94 & \multirow{2}{*}{1.57} & \multirow{2}{*}{0.27} & \multirow{2}{*}{2.43} & \multirow{2}{*}{1.01} \\
\hline$>5$ & 33 & 90 & & & & \\
\hline$\leq 6$ & 63 & 112 & \multirow{2}{*}{1.69} & \multirow{2}{*}{0.28} & \multirow{2}{*}{2.69} & \multirow{2}{*}{1.06} \\
\hline$>6$ & 24 & 72 & & & & \\
\hline$\leq 7$ & 67 & 114 & \multirow{2}{*}{2.06} & \multirow{2}{*}{0.30} & \multirow{2}{*}{3.35} & \multirow{2}{*}{1.26} \\
\hline$>7$ & 20 & 70 & & & & \\
\hline$\leq 8$ & 71 & 119 & \multirow{2}{*}{2.42} & \multirow{2}{*}{0.32} & \multirow{2}{*}{4.08} & \multirow{2}{*}{1.44} \\
\hline$>8$ & 16 & 65 & & & & \\
\hline$\leq 9$ & 73 & 128 & 200 & ?20 & 0 & 120 \\
\hline$>9$ & 14 & 56 & 2.28 & 0.33 & 3.94 & 1.32 \\
\hline$\leq 10$ & 74 & 133 & 10 & & & \\
\hline$>10$ & 13 & 51 & 2.18 & 0.34 & 3.84 & 1.24 \\
\hline$\leq 11$ & 75 & 138 & 00 & זיר 0 & 27 7 & 110 \\
\hline$>11$ & 12 & 46 & L.08 & 0.35 & 3.13 & 1.10 \\
\hline$\leq 12$ & 77 & 152 & 162 & م20 & 207 & 00 \\
\hline$>12$ & 10 & 32 & 1.02 & 0.05 & 0.01 & 0.00 \\
\hline$\leq 18$ & 83 & 173 & ר? 1 & 000 & ? & 010 \\
\hline$>18$ & 4 & 11 & 1.32 & 0.60 & 3.53 & 0.49 \\
\hline
\end{tabular}

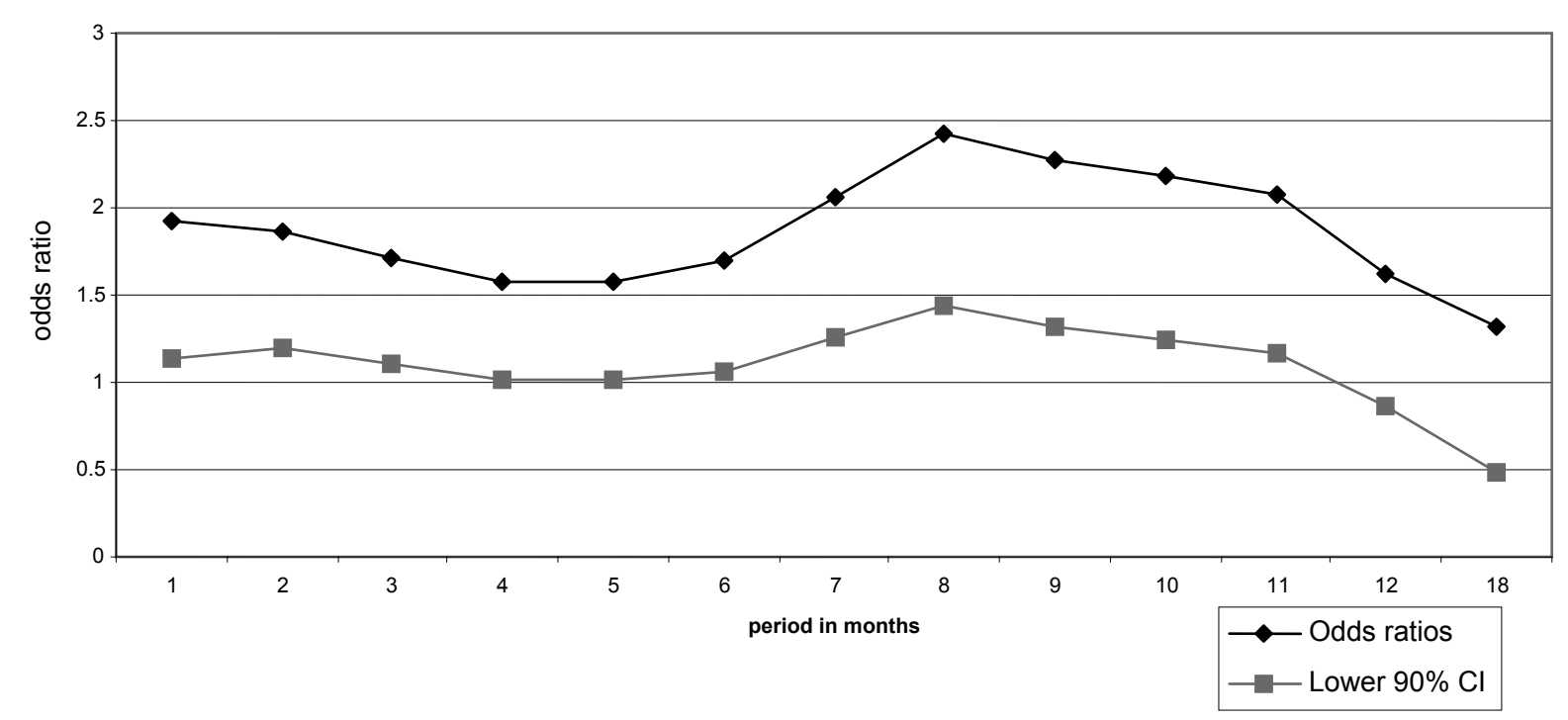

Fig. 1. Odds ratio of the occurrence of acute otitis media according to whether the child was breastfed for less than or more than a certain period. 
significant reduction in the incidence of AOM, but still has a protective effect against the disease (odds ratio $>1$ ), until the 18th month. Furthermore, there is marked variation in the importance of breastfeeding during these first 11 months. There seems to be a vital protective effect during the first 4 months of life, which drops by the 5th month and then rises again from the beginning of the 6th to the end of the 8th month, with the odds ratios actually being highest during this period of development (Fig. 1). It then drops once more, although remaining positive and statistically significant, until the 11th month of life and positive but not statistically significant until the 18th.

\section{DISCUSSION}

In agreement with previous studies, our data show that there is a significant benefit of breastfeeding $(1,2)$ even of minimal duration, with positive effect against AOM (2-9). However, unlike previous studies that have suggested that exclusive breastfeeding for 4 or 6 months is enough to protect infants from single and recurrent episodes of $\mathrm{OM}(2,6,8)$, our results have shown that continuation of breastfeeding for a period of at least 11 months, plays a significant protective role against AOM, with breastfeeding beyond this period, also being protective against AOM, however, without statistical significance.

Our findings are therefore in agreement with the findings of Aniansson et al. (9) who have shown that AOM frequency was significantly lower in children breastfed for up to 10 months and Duffy et al. (7) who have shown that the peak incidence of AOM episodes was inversely related to rates of breastfeeding beyond 3 months of age. Our data also agree with the studies that have shown that long periods of breastfeeding have no side effects on the babies' health $(11,12)$ but they disagree that after a certain point of time they do not offer any extra protective benefit against AOM (13) as according to our data, a protective effect continues to be observed until the 18th month, although this effect is not statistically significant. However, the reference studies mentioned above $(11,12,13)$, were not specifically focused on AOM, unlike ours, but were rather focused on the general health benefits of breastfeeding.

The importance of breastfeeding also seems to vary from month to month and our data indicate that it is vital for the newborn to have the colostrum. Subsequent breastfeeding is still statistically significant but of continuously decreasing importance up to the 5th month. From the 6th month to the 8th month, the importance of continuation of breastfeeding appears to be more important than ever before, even more so than the effect of breastfeeding during the first months and the colostrum. After that, its importance drops but remains significant until the 11th month, after which it is no longer statistically significant despite still showing a positive effect, until the 18th month after birth.

We attribute these findings to the rich immunological content of the colostrum and the first milk, which protects the newborn against its first immunological challenges. By the end of the 5th month the child's protected environment offers no new immunological challenges to its immune system. By the 6th month, the infant starts to be more active and mobile, making its first attempts in sitting and crawling. It gets taken out of its cradle and out of the house more often, starts eating other foods besides breast-milk, and the phase where it starts to bring things to its mouth for exploration, begins. All these bring new antigenic challenges to the young inexperienced immune system and this is when the "teaching" value of the passive immunity passed on by the mother, is proven invaluable.

Relevant bibliography connecting breastfeeding duration to the incidence of AOM is scarce in the last decade. The WHO recommends exclusive breastfeeding for the first 6 months of life and continuation of breast feeding for up to 2 years (14). This recommendation is based mainly on research that debates the age at which complementary feeding should be introduced (15).

In contrast to similar studies $(6,8)$ on which the WHO recommendation is based, the effect of the duration of exclusive breastfeeding was not examined in this study but rather children with continuous intake of breast milk at different ages were compared to the children who did not continue to be breastfed until the corresponding age and the age at which supplementary nutrition was added was not specified. The immunological value of breastfeeding rather than its nutritional value was under examination. Our results are in agreement with the recommendations of the WHO for prolonged breastfeeding although our data are limited up to the 18th month of age. According to our data it is important to breastfeed the child at least to the 11th month of life to effectively prevent the incidence of AOM. Nevertheless further research that adds the parameter of exclusive vs non-exclusive breastfeeding and no breastfeeding will be the next step of our study.

Given that AOM is a multi-factorial disease and the relatively limited number of children involved in this study, there was no way of effectively controlling for all the other contributing factors involved in AOM pathogenesis (i.e. day care duration, allergies, passive smoking, hereditary predisposition, socioeconomic status of the family etc.) and therefore form a clearer picture of the isolated preventive effect of breastfeeding. Further studies, with further optimization of the various risk factors involved, is going to be our next target.

\section{CONCLUSION}

It is evident that it is important for the breastfeeding to continue at least until the 11th month of life, for the optimal effect in the protection against AOM to be seen. The importance of breastfeeding also appears to vary from month to month while the child is being breastfed. It seems that, although it is necessary for the child to be breastfed for 11 months and it would be helpful if it continued breastfeeding until the 18thmonth, it is absolutely vital for children to be breastfed for the first 8 months of its life.

\section{REFERENCES}

1. Hanson LA. Session 1: feeding and infant development Breast-feeding and immune function. Proc Nutr Soc. 2007 Aug;66(3):384-96.

2. Chantry CJ, Howard CR, Auinger P. Full breastfeeding duration and associated decrease in respiratory tract infection in US children. Pediatrics. 2006 Feb;117(2):425-32.

3. Giebink GS. Preventing otitis media. Ann Otol Rhinol Laryngol Suppl. 1994 May;163:20-3.

4. Kero P, Piekkala P. Factors affecting the occurrence of acute otitis media during the first year of life. Acta Paediatr Scand. 1987 Jul;76(4):61823. 
5. Shaaban KM, Hamadnalla I. The effect of duration of breast feeding on the occurrence of acute otitis media in children under three years. East Afr Med J. 1993 Oct;70(10):632-4.

6. Duncan B, Ey J, Holberg CJ, Wright AL, Martinez FD, Taussig LM. Exclusive breast-feeding for at least 4 months protects against otitis media. Pediatrics. 1993 May;91(5):867-72.

7. Duffy LC, Faden H, Wasielewski R, Wolf J, Krystofik D. Exclusive breastfeeding protects against bacterial colonization and day care exposure to otitis media. Pediatrics. 1997 Oct;100(4):E7

8. Daly KA, Brown JE, Lindgren BR, Meland MH, Le CT, Giebink GS. Epidemiology of otitis media onset by six months of age. Pediatrics. 1999 Jun;103(6 Pt 1):1158-66.

9. Aniansson G, Alm B, Andersson B, Hakansson A, Larsson P, Nylen O, et al. A prospective cohort study on breast-feeding and otitis media in Swedish infants. Pediatr Infect Dis J. 1994 Mar;13(3):183-8.

10. Dewey KG, Heinig MJ, Nommsen-Rivers LA. Differences in morbidity between breast-fed and formula-fed infants. J Pediatr. 1995 May;126(5 Pt 1):696-702.
11. Kramer MS, Kakuma R. Optimal duration of exclusive breastfeeding. Cochrane Database Syst Rev. 2002;(1):CD003517.

12. Kramer MS, Kakuma R. The optimal duration of exclusive breastfeeding: a systematic review. Adv Exp Med Biol. 2004;554:63-77.

13. Howie PW, Forsyth JS, Ogston SA, Clark A, Florey CD. Protective effect of breast feeding against infection. BMJ. 1990 Jan 6;300(6716):11-6.

14. World Health Organization [homepage on the Internet]. Geneva: WHO Nutrition [cited 2007 Mar 8]. The World Health Organization's infant feeding recommendation. Available from: http://www.who.int/nutrition/ topics/infantfeeding_recommendation/en/index.html.

15. Dewey KG. What is the optimal age for introduction of complementary foods? Nestle Nutr Workshop Ser Pediatr Program. 2006;58:161-70; discussion 170-5.

Received March 8, 2007 Accepted in revised form August 30, 2007 